\title{
A chemical probe selectively inhibits G9a and GLP methyltransferase activity in cells
}

\author{
Masoud Vedadi ${ }^{1,12}$, Dalia Barsyte-Lovejoy ${ }^{1,12}$, Feng Liu'2,12, Sylvie Rival-Gervier ${ }^{3,5}$, \\ Abdellah Allali-Hassani ${ }^{1}$, Viviane Labrie ${ }^{6}$, Tim J Wigle ${ }^{2}$, Peter A Dimaggio ${ }^{7}$, Gregory A \\ Wasney $^{1}$, Alena Siarheyeva ${ }^{1}$, Aiping Dong ${ }^{1}$, Wolfram Tempel ${ }^{1}$, Sun-Chong Wang ${ }^{6,8}$, Xin \\ Chen $^{2}$, Irene Chau ${ }^{1}$, Thomas J Mangano ${ }^{9}$, Xi-ping Huang ${ }^{9}$, Catherine D Simpson ${ }^{2}$, \\ Samantha G Pattenden ${ }^{2}$, Jacqueline L Norris ${ }^{2}$, Dmitri B Kireev ${ }^{2}$, Ashutosh Tripathy ${ }^{10}$, Aled \\ Edwards ${ }^{1}$, Bryan L Roth ${ }^{9}$, William P Janzen ${ }^{2}$, Benjamin A Garcia ${ }^{7}$, Arturas Petronis ${ }^{6}$,

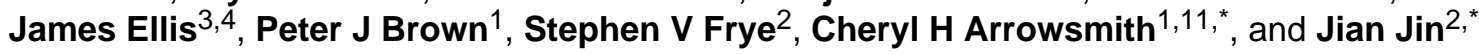 \\ ${ }^{1}$ Structural Genomics Consortium, University of Toronto, Toronto, Ontario, Canada \\ ${ }^{2}$ Center for Integrative Chemical Biology and Drug Discovery, Division of Medicinal Chemistry \\ and Natural Products, UNC Eshelman School of Pharmacy, University of North Carolina at \\ Chapel Hill, Chapel Hill, North Carolina, USA \\ ${ }^{3}$ Developmental and Stem Cell Biology Program, SickKids Hospital, Toronto, Ontario, Canada \\ ${ }^{4}$ Department of Molecular Genetics, University of Toronto, Toronto, Ontario, Canada \\ 5INRa, UMR 1198 Biologie du Développement et Reproduction, Jouy en Josas, France \\ ${ }^{6}$ Krembil Family Epigenetic Laboratory, Centre for Addiction and Mental Health, Toronto, Ontario, \\ Canada \\ ${ }^{7}$ Department of Chemistry, Princeton University, Princeton, New Jersey, USA \\ ${ }^{8}$ Institute of Systems Biology and Bioinformatics, National Central University, Jhongli City, Taiwan \\ ${ }^{9}$ National Institute of Mental Health Psychoactive Drug Screening Program, University of North \\ Carolina at Chapel Hill, Chapel Hill, North Carolina, USA \\ ${ }^{10}$ Department of Biochemistry and Biophysics, UNC Macromolecular Interactions Facility, \\ University of North Carolina at Chapel Hill, Chapel Hill, North Carolina, USA
}

@ 2011 Nature America, Inc. All rights reserved
*carrow@uhnres.utoronto.ca. ${ }^{*}$ jianjin@ unc.edu.
12 These authors contributed equally to this work.

Author contributions M.V., A.A.-H., A.S. and I.C. performed SAHH-coupled, fluorescence-polarization, DSF, DSLS and DNMT1 assays; D.B.-L. developed and performed in-cell western, MTT, ChIP, gene expression, clonogenicity, western blotting and immunofluorescence studies; F.L. developed the synthetic route to UNC0638 and UNC0737 and synthesized the compounds; S.R.-G. and J.E. developed and performed mES cell studies; V.L., S.-C.W. and A.P. performed H3K9me2 genomic localization and DNA methylation analysis; T.J.W. and W.P.J. performed mechanism-of-action studies; P.A.D. and B.A.G. performed MS-based proteomics studies; M.V., G.A.W., A.D., W.T., D.B.K. and C.H.A. solved and analyzed the X-ray crystal structure of the G9a-UNC0638-SAH complex; T.J.W. and A.T. performed SPR studies; X.C. and S.G.P. performed UNC0638 stability studies; S.G.P. performed RT-qPCR studies; T.J.M., X.-p.H. and B.L.R. performed GPCR selectivity studies; C.D.S. and W.P.J. performed kinase selectivity studies; J.L.N. purified proteins; J.J. designed UNC0638 and UNC0737; C.H.A., J.J., S.V.F., M.V., D.B.-L., P.J.B., J.E., S.R.-G., A.P., V.L., B.A.G., T.J.W. and A.E. designed studies and discussed results; J.J., C.H.A., D.B.-L., S.R.-G., M.V., V.L., S.V.F., J.E., A.P., B.A.G., P.J.B. and T.J.W. wrote the paper.

Competing financial interests The authors declare no competing financial interests.

Additional information Supplementary information, chemical compound information and chemical probe information is available online at http://www.nature.com/naturechemicalbiology/. Reprints and permissions information is available online at

http://www.nature.com/reprints/index.html. Correspondence and requests for materials should be addressed to C.H.A. and J.J. 
${ }^{11}$ Ontario Cancer Institute, Campbell Family Cancer Research Institute and Department of Medical Biophysics, University of Toronto, Toronto, Ontario, Canada

\section{Abstract}

Protein lysine methyltransferases G9a and GLP modulate the transcriptional repression of a variety of genes via dimethylation of Lys9 on histone $\mathrm{H} 3(\mathrm{H} 3 \mathrm{~K} 9 \mathrm{me} 2)$ as well as dimethylation of non-histone targets. Here we report the discovery of UNC0638, an inhibitor of G9a and GLP with excellent potency and selectivity over a wide range of epigenetic and non-epigenetic targets.

UNC0638 treatment of a variety of cell lines resulted in lower global H3K9me2 levels, equivalent to levels observed for small hairpin RNA knockdown of G9a and GLP with the functional potency of UNC0638 being well separated from its toxicity. UNC0638 markedly reduced the clonogenicity of MCF7 cells, reduced the abundance of $\mathrm{H} 3 \mathrm{~K} 9 \mathrm{me} 2$ marks at promoters of known G9a-regulated endogenous genes and disproportionately affected several genomic loci encoding microRNAs. In mouse embryonic stem cells, UNC0638 reactivated G9a-silenced genes and a retroviral reporter gene in a concentration-dependent manner without promoting differentiation.

Protein lysine methylation is increasingly recognized as a major signaling mechanism in eukaryotic cells. This process has been most heavily studied in the context of epigenetic regulation of gene expression through methylation of lysine residues of histone proteins ${ }^{1-6}$, but a growing number of known non-histone substrates suggest that the impact of lysine methylation is not limited to chromatin biology ${ }^{7-10}$. Protein lysine methyltransferases (PKMTs) catalyze the transfer of a methyl group from $S$-adenosyl-ı-methionine (SAM) to the $\varepsilon$-amino group of lysine residues of proteins, including histones ${ }^{1,11}$. Since the first PKMT was characterized in 2000 (ref. 12), more than 50 human PKMTs have been identified $^{1,11}$. PKMTs show substantial variations in protein substrate selectivity and the degree of methylation on lysine, from mono- to di- to trimethylation. Selective pharmacological inhibition of individual PKMTs' catalytic activity in cellular systems is a useful strategy for deciphering the complex signaling mechanisms of histone and protein lysine methylation. However, very few small-molecule tools are currently available for probing the activity of individual PKMTs ${ }^{13}$.

Growing evidence suggests that PKMTs are important in the development of various human disease ${ }^{11,14}$. In particular, G9a (also known as KMT1C or EHMT2), which was initially identified as a histone H3 Lys9 (H3K9) methyltransferase ${ }^{15}$, is overexpressed in various human cancers including leukemia ${ }^{8}$, prostate carcinoma ${ }^{8,16}$, hepatocellular carcinoma ${ }^{17}$ and lung cancer ${ }^{18}$. It has been shown that knockdown of G9a inhibits prostate, lung and leukemia cancer cell growth ${ }^{16,18,19}$. The closely related protein GLP (also known as KMT1D or EHMT1) shares $80 \%$ sequence identity with G9a in their respective SET domains and forms a heterodimer with $\mathrm{G} 9 \mathrm{a}^{20}$. In addition to catalyzing mono- and dimethylation of H3K9 (refs. 15,20), both G9a and GLP dimethylate Lys373 of the tumor suppressor p53, inactivating p53's transcriptional activity ${ }^{8}$. Moreover, G9a has been shown to be involved in cocaine addiction ${ }^{21}$, mental retardation ${ }^{22}$, maintenance of HIV-1 latency ${ }^{23}$ and DNA methylation in mouse embryonic stem $(\mathrm{mES})$ cells $^{24-26}$. Furthermore, pharmacologic inhibition of G9a and GLP has been reported to facilitate reprogramming of mouse fetal neural precursor cells into induced pluripotent stem (iPS) cells ${ }^{27,28}$. This broad range of cellular and disease-related activities poses a challenge for understanding G9a- and GLP-related biology and for the potential targeting of these proteins therapeutically. Thus, selective, potent and cell- active chemical probes for G9a and GLP would be extremely valuable tools for investigating the cellular role of these PKMTs, as well as for assessing their potential as therapeutic targets. 
The recent report of BIX01294 (1), a small-molecule inhibitor of G9a and GLP29, was an important advance, as this compound is, to our knowledge, the first potent and selective PKMT inhibitor. BIX01294 has since been used successfully as a probe of G9a in cellular reprogramming 27,28 and reactivation of latent HIV-1 (ref. 23). BIX01294 at $4.1 \mu \mathrm{M}$ reduced the abundance of the H3K9me2 mark in bulk histones in several cell lines and reduced H3K9me2 levels at G9a target genes ${ }^{29}$. However, BIX01294 was toxic to cells at concentrations higher than $4.1 \mu \mathrm{M}$ (ref. 29). This poor separation between the concentration producing robust functional effects in cells and the concentration causing toxicity has limited the compound's usefulness as a G9a and GLP chemical probe. To provide a highquality chemical probe ${ }^{30}$ of G9a and GLP with an improved ratio of toxicity to functional potency (toxicity/function ratio, which is determined dividing the $\mathrm{EC}_{50}$ value of observed toxicity by the $\mathrm{IC}_{50}$ value of the functional potency), we have explored this 2,4-diamino-6,7dimethoxyquinazo-line template. We have previously reported the discovery of UNC0224 and UNC0321 (2) as potent and selective G9a and GLP inhibitors and described robust structure-activity relationships (SAR) of their analogs ${ }^{31,32}$. Other studies of the SAR of this scaffold have resulted in the discovery of E72 as a potent and selective GLP inhibitor ${ }^{33}$. However, UNC0321 (Supplementary Results, Supplementary Fig. 1) and E72 (ref. 33) are less potent than BIX01294 in cellular assays.

Here we report that UNC0638 (3) is a potent, selective and cell-penetrant chemical probe for G9a and GLP, with a toxicity/function ratio of $>100$, compared to $<6$ for BIX01294. We describe the discovery of UNC0638 and its in vitro potency, selectivity, mechanism of action and kinetics, X-ray cocrystal structure and robust on-target activities in cells. This greatly improved, well-characterized chemical probe represents a substantial advance in PKMT probe discovery and will enable better understanding of the epigenetic and cellular role(s) of G9a and GLP.

\section{RESULTS}

\section{Discovery of UNC0638}

Previously, initial inhibitor design and synthesis based on the X-ray cocrystal structures of the GLP-BIX01294 (PDB 3FPD) ${ }^{34}$ and G9a- UNC0224 (PDB 3K5K) ${ }^{31}$ complexes led us to discover UNC0321, a potent and selective inhibitor of G9a and GLP ${ }^{32}$ (Scheme 1).

However, UNC0321 was less potent in cellular assays than BIX01294 (Supplementary Fig. 1), even though it was more potent than BIX01294 in biochemical assays. We hypothesized that the poor cellular potency of UNC0321 was probably due to poor cell membrane permeability. Here, to improve the cellular potency of this series of compounds, we exploited the SAR of the quinazoline scaffold discovered previously 31,32 and designed several generations of new analogs aimed at increasing lipophilicity while maintaining high in vitro potency. Among the newly synthesized compounds, UNC0638 (Scheme 1), which has balanced in vitro potency and physicochemical properties aiding cell penetration, showed high potency in cellular assays and was considerably less toxic to cells than BIX01294 (see below). UNC0638 was efficiently synthesized via a novel seven-step synthetic sequence (Supplementary Scheme 1). In contrast to our previous synthetic route to UNC0321 (ref. 32), this new synthesis avoided the Mitsunobu reaction as the last synthetic step and thus greatly facilitated purification of the final compounds.

In addition, we designed and synthesized UNC0737 (4) (Scheme 1), the $N$-methyl analog of UNC0638, as a structurally similar but less potent G9a and GLP inhibitor for use as a negative control. UNC0737 was designed to eliminate the hydrogen bond interaction seen in the G9a-UNC0224 cocrystal structure between Asp1083 of G9a and the secondary amino group at the 4-position of UNC0224's quinazoline ring ${ }^{31}$. Indeed, UNC0737 was >300-fold less potent than UNC0638 in G9a and GLP biochemical assays (see below). 


\section{UNC0638 is a potent and substrate-competitive inhibitor}

The inhibitory effect of UNC0638 on G9a and GLP activity was first evaluated using the fluorescence-based $S$-adenosyl-ı-homocysteine hydrolase (SAHH)-coupled assay, which monitors the conversion of the cofactor, SAM, to the cofactor product, $S$-adenosyl-Lhomocysteine $(\mathrm{SAH})^{35}$. UNC0638 was a potent $\mathrm{G} 9 \mathrm{a}\left(\mathrm{IC}_{50}<15 \mathrm{nM}(n=4)\right)$ and GLP inhibitor $\left(\mathrm{IC}_{50}=19 \pm 1 \mathrm{nM}(n=2)\right)$ in these SAHH-coupled assays (Table 1). An endoproteinase-coupled microfluidic capillary electrophoresis (MCE) assay ${ }^{36}$, which is orthogonal and complementary to the SAHH-coupled assay, was also used to evaluate G9a inhibition by UNC0638, yielding an $\mathrm{IC}_{50}<10 \mathrm{nM}(n=3)$. In addition, UNC0638 displaced a fluorescein-labeled 15-mer $\mathrm{H} 3$ peptide (residues 1-15) with high efficiency in a G9a fluorescence-polarization assay, suggesting that UNC0638 binds in the substrate peptidebinding site of G9a (Supplementary Fig. 2). UNC0638 also stabilized G9a and GLP in differential scanning fluorimetry (DSF) experiments, with Tm shifts of $4{ }^{\circ} \mathrm{C}$ and $8{ }^{\circ} \mathrm{C}$, respectively, consistent with high-affinity binding (Supplementary Fig. 3).

We next determined detailed mechanism-of-action and Michaelis-Menten kinetic parameters associated with both the peptide and SAM as a function of UNC0638 concentration (Fig. 1a-d). These experiments confirmed that UNC0638 was competitive with the peptide substrate, as the $K_{\mathrm{m}}$ of the peptide ( $\left.K_{\mathrm{m}}{ }^{\text {peptide }}\right)$ increased linearly with UNC0638 concentration (Fig. 1b), and noncompetitive with cofactor SAM, as the apparent $K_{\mathrm{m}}$ of SAM $\left(K_{\mathrm{m}}{ }^{\mathrm{app}}\right)$ remained constant in the presence of increasing concentrations of the compound (Fig. 1d). The $K_{\mathrm{i}}$ of UNC0638 was determined to be $3.0 \pm 0.05 \mathrm{nM}(n=2)$. Consistent with this, the Morrison $K_{\mathrm{i}}$ (ref. 37) for UNC0638 was $3.7 \pm 0.2 \mathrm{nM}(n=3)$ (Supplementary Fig. $4)$.

Kinetics of the inhibition of G9a by UNC0638 was also studied using surface plasmon resonance (SPR). UNC0638 bound G9a tightly, with rapid association $\left(k=2.12 \times 10^{6} 1 / \mathrm{Ms}\right)$ and disassociation $\left(k_{\mathrm{d}}=5.7 \times 10^{-2} 1 / \mathrm{s}\right)$ rates (Supplementary Fig. 5), consistent with a classic reversible mechanism of inhibition of G9a. The $K_{\mathrm{d}}$ of UNC0638 measured from equilibrium analysis of the Langmuir binding isotherms in the SPR studies was $27 \mathrm{nM}$, consistent with results from homogeneous assays.

As expected, UNC0737, the $\mathrm{N}$-methyl analog of UNC0638, was a poor inhibitor of G9a $\left(\mathrm{IC}_{50}=5,000 \pm 200 \mathrm{nM}(n=2)\right)$ and GLP $\left(\mathrm{IC}_{50}>10,000 \mathrm{nM}(n=2)\right)$ in the SAHH-coupled assays (Supplementary Table 2). The combination of the high structural similarity between UNC0737 and UNC0638 and the >300-fold loss of potency in UNC0737 compared to UNC0638 makes UNC0737 an appropriate negative control for use in cellular and functional assays.

\section{UNC0638 is a selective inhibitor of G9a and GLP}

The selectivity of UNC0638 over a wide range of epigenetic targets was evaluated (Table 1). Notably, UNC0638 was inactive against other H3K9 (SUV39H1 and SUV39H2), H3K27 (EZH2), H3K4 (SETD7, MLL and SMYD3), H3K79 (DOT1L) and H4K20 (SETD8) methyltransferases, as well as PRDM1, PRDM10 and PRDM12. In addition, UNC0638 was inactive against protein arginine methyltransferases PRMT1 and PRMT3, and HTATIP, a histone acetyltransferase. Of note, UNC0638 had weak but measurable activity against JMJD2E $\left(\mathrm{IC}_{50}=4,500 \pm 1,100 \mathrm{nM}(n=3)\right)$, a Jumonji protein demethylase and DNA methyltransferase DNMT1 $\left(\mathrm{IC}_{50}=107,000 \pm 6,000 \mathrm{nM}(n=2)\right)$. Nevertheless, the selectivity of UNC0638 for G9a and GLP over JMJD2E was >200-fold, and selectivity for G9a and GLP over DNMT1 was >5,000-fold.

We also evaluated the selectivity of UNC0638 over a broad range of non-epigenetic targets, including G protein coupled receptors (GPCRs), ion channels, transporters and kinases 
(Supplementary Tables 3 and 4). UNC0638 was clean ( $<30 \%$ inhibition at $1 \mu \mathrm{M})$ against 26 out of 29 targets in the Ricerca Selectivity Panel. At $1 \mu \mathrm{M}$ concentration, UNC0638 showed $64 \%, 90 \%$ and $69 \%$ inhibition of muscarinic $\mathrm{M}_{2}$, adrenergic $\mathrm{a}_{1 \mathrm{~A}}$ and adrenergic $\mathrm{a}_{1 \mathrm{~B}}$ receptors, respectively. Because UNC0638 hit three GPCRs in the Ricerca Selectivity Panel, we further assessed its selectivity against GPCRs by testing UNC0638 in the US National Institute of Mental Health's Psychoactive Drug Screen Program Selectivity Panel, which consists of a total of 45 targets, including 36 GPCRs. UNC0638 had $<50 \%$ inhibition at 1 $\mu \mathrm{M}$ against 39 targets in the panel, and $>50 \%$ inhibition at $1 \mu \mathrm{M}$ against 6 targets in the panel. $K_{\mathrm{i}}$ in the radio-ligand binding assay for each of the six interacting GPCRs was subsequently determined. The $K_{\mathrm{i}}$ measurements showed UNC0638 was at least 100 -fold selective for G9a over these six GPCRs. In $\mathrm{M}_{1}, \mathrm{M}_{2}$ and $\mathrm{M}_{4}$ functional assays, UNC0638 had no agonist activity, low antagonist potency against $\mathrm{M}_{1}$ and $\mathrm{M}_{4}\left(\mathrm{IC}_{50}>10,000 \mathrm{nM}(n=2)\right)$, and modest antagonist potency against $\mathrm{M}_{2}\left(\mathrm{IC}_{50}=480 \pm 10 \mathrm{nM}(n=2)\right)$. Furthermore, UNC0638 was tested against a panel of 24 kinases and showed $<10 \%$ inhibition at $1 \mu \mathrm{M}$ against these kinases. Therefore, we conclude that when used at appropriate concentrations (for example, $<500 \mathrm{nM}$ ), the effects of UNC0638 on histone or other lysine methylation substrates can be interpreted as primarily due to the inhibition of G9a and GLP.

The selectivity of UNC0737 is summarized in Supplementary Table 2. Like UNC0638, UNC0737 was inactive against SUV39H2, SETD7, SETD8 and PRMT3, had a bindingaffinity range of 60 to $1,000 \mathrm{nM}$ ( $K_{\mathrm{i}}$ values) for $\mathrm{a}_{1 \mathrm{~A}}, \mathrm{a}_{2 \mathrm{C}}, \mathrm{M}_{1}, \mathrm{M}_{2}$ and $\mathrm{M}_{4}$ receptors, had low to modest potency $\left(\mathrm{IC}_{50} 800\right.$ to $>10,000 \mathrm{nM}$ ) in $\mathrm{M}_{1}, \mathrm{M}_{2}$ and $\mathrm{M}_{4}$ functional assays and was inactive against a panel of 24 kinases. The similar molecular profiles of UNC0737 and UNC0638 against epigenetic targets (except G9a and GLP) and non-epigenetic targets make UNC0737 an appropriate negative control in terms of selectivity.

\section{Crystal structure of the G9a-UNC0638-SAH complex}

An X-ray crystal structure of the G9a-UNC0638-SAH complex (2.56-Å resolution; Fig. 1e,f and Supplementary Table 1) provides structural insight into the mechanism of action. First, UNC0638 occupies the substrate binding groove and does not interact with the SAM binding pocket. This finding is consistent with the results from the inhibitor-peptide-SAM competition experiments. Second, the hydrogen of the secondary amino group at the 4position of the quinazoline ring indeed forms a hydrogen bond with Asp1083, explaining the marked potency loss of UNC0737 compared to UNC0638. Finally, the lysine binding channel is occupied by the 7-(3-pyrrolidin-1-yl-)propoxy side chain. Compared to the X-ray crystal structures of the GLP-BIX01294 (PDB 3FPD) ${ }^{34}$ and G9a- UNC0224 (PDB 3K5K) ${ }^{31}$ complexes, the same binding mode was observed for UNC0638 (Supplementary Fig. 6).

\section{UNC0638 is stable under cellular assay conditions}

${ }^{1} \mathrm{H}$ NMR and LC-MS analysis of a solution of UNC0638 (10 mM) in deuterated DMSO and deuterated $\mathrm{H}_{2} \mathrm{O}$ (90:10 ratio) that had been kept at room temperature for 4 weeks indicated that UNC0638 was stable under these conditions; no degradation products were found. Incubation of UNC0638 with or without MCF7, U2OS or H1299 cells in two types of cell media for $65 \mathrm{~h}$ also did not produce degradation products of UNC0638. In mouse drug metabolism and pharmacokinetic studies, UNC0638 had high clearance, short half-life, high volume distribution and low exposure after intravenous, oral or intraperitoneal administration (Supplementary Table 5). Thus, although UNC0638 is probably not suitable for in vivo animal studies owing to low exposure levels, its high stability under cellular assay conditions, in combination with high potency and selectivity, makes UNC0638 an ideal chemical tool for cell-based studies. 


\section{UNC0638 has high cellular potency and low toxicity}

G9a and GLP are the primary enzymes affecting dimethylation of histone H3K9 in cells ${ }^{15,20}$. To assess the cellular potency of UNC0638, we used an H3K9me2 antibody cell immunofluorescence or in-cell western assay. This assay allows rapid processing of multiple samples for $\mathrm{H} 3 \mathrm{~K} 9 \mathrm{me} 2 \mathrm{immunofluorescence} \mathrm{signal} \mathrm{(Fig.} \mathrm{2a,} \mathrm{green} \mathrm{signal)} \mathrm{and} \mathrm{normalization}$ to cell number via the use of the nucleic acid dye DRAQ5 (Fig. 2a, red signal). We verified the specificity of the antibody by comparison of dose-dependent dot blots and by the reduced cellular immunofluorescence signal in G9a and GLP knockdown experiments (Fig. 2a). Initially, the data were normalized to total $\mathrm{H} 3$ levels (Supplementary Fig. 7); however, this was found to be consistent with the DRAQ5 normalization, and subsequently the latter was used. We characterized UNC0638 and UNC0737 in MDA-MB-231 cells because of their robust H3K9me2 levels and good tolerance of G9a and GLP knockdown. In MDAMB-231 and MCF7 cells, treatment with several short hairpin RNAs (shRNAs) reduced G9a and GLP to $25-40 \%$ of the levels in control experiments, and also yielded consistently lower levels of H3K9me2 (Supplementary Fig. 8). In MDA-MB-231 cells, UNC0638 (48 h exposure) reduced $\mathrm{H} 3 \mathrm{~K} 9 \mathrm{me} 2$ levels in a concentration-dependent manner with an $\mathrm{IC}_{50}$ of 81 $\pm 9 \mathrm{nM}(n=3)$, which indicates considerably higher potency than BIX01294 $\left(\mathrm{IC}_{50}=500 \pm\right.$ $43 \mathrm{nM}(n=3))$ (Fig. 2b). The maximum effect of UNC0638 in reducing H3K9me2 levels was greater than that of BIX01294 and close, but not equal, to that of the double knockdown of G9a and GLP via shRNA (Fig. 2b). Consistent with its poor in vitro potency, UNC0737 (negative control) showed poor cellular potency in the in-cell western $\left(\mathrm{IC}_{50}>5,000 \mathrm{nM}(n=\right.$ 3); Fig. 2b) and chromatin immunoprecipitation (ChIP) assays (Supplementary Fig. 9).

We next studied the time course of effects of UNC0638 on cellular levels of H3K9me2. Because H3K9me2 has a half-life of about $1 \mathrm{~d}$ (ref. 38), we hypothesized that exposure beyond $48 \mathrm{~h}$ might result in even greater reduction of the mark. We found that $\mathrm{H} 3 \mathrm{~K} 9 \mathrm{me} 2$ levels in MDA-MB-231 cells gradually decreased over the course of treatment (Fig. 2c). After $4 \mathrm{~d}$, the cellular H3K9me2 levels under treatment with 250 or $500 \mathrm{nM}$ of UNC0638 were equal or very close to those of G9a and GLP knockdown cells. At both UNC0638 concentrations, changing the cell medium after $2 \mathrm{~d}$ (denoted " $2+2 \mathrm{~d}$ " in Fig. 2c) had little effect compared with not changing the medium (denoted " $4 d$ " in Fig. 2c). Notably, reduced cellular levels of $\mathrm{H} 3 \mathrm{~K} 9 \mathrm{me} 2$ were still observed at the 4-d time point after cells were exposed to UNC0638 for $2 \mathrm{~d}$, followed by washout of the compound and another $2 \mathrm{~d}$ of culture without the inhibitor (denoted " $2+2 \mathrm{dw}$ " in Fig. $2 \mathrm{c}$ ). The level of H3K9me2 at day $2+2 \mathrm{dw}$ was inversely proportional to the original dosage of UNC0638, suggesting that residual amounts of UNC0638 remain in the cells and can have a lasting effect. Inhibitor treatment did not affect the protein levels of G9a or GLP (Supplementary Fig. 10) or the mRNA levels of G9a (Supplementary Fig. 11), indicating the observed effects were due to inhibition of the enzymatic function of the proteins and not to changes in protein abundance.

One of the desirable characteristics of a good chemical probe is low toxicity due to off-target effects. Both UNC0638 $\left(\mathrm{EC}_{50}=11,000 \pm 710 \mathrm{nM}(n=3)\right)$ and $\mathrm{UNC} 0737\left(\mathrm{EC}_{50}=8,700 \pm\right.$ $790 \mathrm{nM}(n=3))$ were considerably less toxic than BIX01294 $\left(\mathrm{EC}_{50}=2,700 \pm 76 \mathrm{nM}(n=\right.$ 3)) in an MTT assay (Fig. 2d). Notably, UNC0737 had cellular toxicity similar to that of UNC0638, suggesting that the observed cellular toxicity is probably not due to inhibition of G9a and GLP in this cell type. Thus, the toxicity/function ratio of UNC0638 was 138, whereas the same ratio for BIX01294 was <6 (Fig. 2e,f). This much improved toxicity/ function ratio enables UNC0638 to be used in cell-based model systems over a range of concentrations without interference from cellular toxicity.

Furthermore, we have evaluated the cellular potency and toxicity of UNC0638 in other tumor and normal cell lines. UNC0638 had high potency, ranging from 48 to $238 \mathrm{nM}$, in reducing $\mathrm{H} 3 \mathrm{~K} 9 \mathrm{me} 2$ levels in breast, prostate, colon carcinomas and normal fibroblast cells, 
with the two prostate carcinoma cell lines, PC3 $\left(\mathrm{IC}_{50}=59 \mathrm{nM}\right)$ and $22 \mathrm{RV} 1\left(\mathrm{IC}_{50}=48 \mathrm{nM}\right)$, being the most sensitive (Supplementary Table 6). The $\mathrm{EC}_{50}$ for the cellular toxicity of UNC0638 (from MTT assays) in these tumor and normal cell lines was considerably higher than the corresponding $\mathrm{IC}_{50}$ for the functional effects. The toxicity/function ratio of UNC0638 in these cell lines varied by up to ten-fold (19 for IMR90 compared with 233 for PC3), but was well above the value of 6 observed for BIX01294 in MDA-MB-231 cells.

These results again support the conclusion that UNC0638 is suitable as a chemical probe of G9a and GLP in a broad range of cell types without interference from potential off-target toxicity.

Although UNC0638 is well tolerated by several cell types in terms of general cell viability, we investigated whether it might affect the growth properties of cancer cell lines. At concentrations of UNC0638 that considerably reduce H3K9me2 levels and for which acute off-target toxicity is minimal, we monitored the effect of G9a and GLP inhibi tion on cell growth using a clonogenicity assay. There was a marked concentration-dependent reduction of clonogenicity in MCF7 cells upon treatment with UNC0638 or upon G9a or GLP knockdown but much less effect on MDA-MB-231 cells (Supplementary Fig. 12). These data show that inhibition of G9a and GLP can have differential phenotypic effects depending on the cell type, possibly related to differences in epigenetic state or p53 status (MCF7 cells have functional p53, whereas MDA-MB-231 cells do not).

\section{MS analysis confirms that UNC0638 reduces H3K9me2 levels}

To confirm the effect of UNC0638 on cellular levels of H3K9me2 and assess the potential effect on other histone post-translational modification marks, we analyzed acid-extracted histones from MDA-MB-231 cells treated with UNC0638 using quantitative MS-based proteomics as previously described ${ }^{39}$. After treatment of MDA-MB-231 cells with UNC0638 ( $1 \mu \mathrm{M}$ for $48 \mathrm{~h}$ ), the levels of H3K9me2 were considerably lower, similar to those observed with shRNA double knockdown of G9a and GLP (Fig. 3a,b). BIX01294 (1 $\mu \mathrm{M}$ for $48 \mathrm{~h}$ ) reduced the cellular levels of $\mathrm{H} 3 \mathrm{~K} 9 \mathrm{me} 2$ to a lesser extent than UNC0638 did. These results are consistent with the findings from the in-cell western assay. We note that the levels of unmodified H3K9 were higher upon treatment with UNC0638, consistent with decreased modification by G9a and GLP (Supplementary Fig. 13). In contrast, the levels of H3K9me3 remained constant with all treatments (Fig. 3c,d), suggesting that, at least in these cells, trimethylation of $\mathrm{H} 3 \mathrm{~K} 9$ is not dependent on prior dimethylation of $\mathrm{H} 3 \mathrm{~K} 9$ by G9a and/ or GLP. We also analyzed other well-known histone marks after treatment with UNC0638, BIX01294 and shRNAs targeting G9a and GLP. With the exception of acetylation of histone H3 Lys14 (H3K14ac), no changes in abundance were observed for 21 different modification states of H3 and H4 (Supplementary Table 7). Notably, the levels of H3K14ac doubled both with UNC0638 treatment and with G9a and GLP knockdown, suggesting a possible link or cross-talk between H3K9me2 and H3K14ac (Supplementary Fig. 13). This result is consistent with a previous finding in HEK293 cells in which G9a and GLP were knocked down via siRNA ${ }^{39}$.

\section{Genomic profiling of UNC0638-modulated H3K9me2 levels}

To better understand how UNC0638 might regulate specific genes, we investigated the H3K9me2 levels at genomic loci along chromosomes 3 and X (chr3 and chrX). In chromatin immunoprecipitation on chip (ChIP-chip) experiments using a selective H3K9me2 antibody, MCF7 cells treated with UNC0638 at $320 \mathrm{nM}$ (the $\mathrm{IC}_{90}$ for $\mathrm{H} 3 \mathrm{~K} 9 \mathrm{me} 2$ inhibition) for $14 \mathrm{~d}$ had significantly fewer genomic regions containing $\mathrm{H} 3 \mathrm{~K} 9 \mathrm{me} 2$ on chr3 and chrX $(P<2.2 \times$ $10^{-16}$; Fig. 4a and Supplementary Fig. 14). Lower levels of H3K9me2 were observed in the MAGEA1 promoter in our ChIP-chip study ( $P=4.3 \times 10^{-3}$; Fig. $\left.4 \mathrm{~b}\right)$, and this was confirmed in an independent ChIP-quantitative PCR (ChIP-qPCR) analysis. In agreement 
with previously reported data ${ }^{29}$, our ChIP-chip and ChIP-qPCR data show significant, concentration-dependent reductions of $\mathrm{H} 3 \mathrm{~K} 9 \mathrm{me} 2$ levels at the TBC1D5 and MAGEA2 promoters $\left(P=2.0 \times 10^{-10}\right.$ and $2.6 \times 10^{-3}$, respectively) but not at the MAGEB4 promoter $(P=0.07)$ after exposure to UNC0638 (Supplementary Fig. 15a-c). Thus, UNC0638 shows robust on-target modulation of $\mathrm{H} 3 \mathrm{~K} 9 \mathrm{me} 2$ levels, consistent with its activity as a selective G9a and GLP inhibitor.

H3K9me2 is modestly correlated with euchromatic silenced genes ${ }^{40,41}$; however, it has also been reported at active genes ${ }^{42}$. Notably, when we examined the genes with the greatest reduction of H3K9me2 levels within their gene bodies, we found an enrichment of miRNA genes: $25 \%$ of the top 100 most affected genes encoded miRNAs, whereas only $5 \%$ of the probed genes on chr3 and chrX were miRNA genes (Supplementary Table 8). Furthermore, under the conditions of these experiments (treatment for $14 \mathrm{~d}$ at 70 or $320 \mathrm{nM}$ ), we found that the total levels of DNA methylation were not altered on chr3 and chrX in UNC0638treated MCF7 cells compared to control-treated cells (Fig. 4c and Supplementary Fig. 15d). G9a inactivation has previously been shown to be ineffective in altering global DNA methylation in human cancer cell lines (in contrast to $\mathrm{mES}$ cells) ${ }^{24}$. We note that although our result supports the conclusion that inhibition of G9a catalytic activity does not produce global changes in genomic DNA methylation, it does not exclude the possibility of small, targeted changes below the resolution of these experiments. Taken together, these results further support the value of UNC0638 as a tool for investigating the effects of specific and global changes to $\mathrm{H} 3 \mathrm{~K} 9 \mathrm{me} 2$ levels in human cells.

\section{UNC0638 reactivates silenced gene expression in mES cells}

Embryonic stem cells are unique in their ability to efficiently silence retroviruses through epigenetic mechanisms including $\mathrm{H} 3 \mathrm{~K} 9$ dimethylation ${ }^{43}$. To investigate the ability of UNC0638 to reactivate silent retrovirus vectors, we first determined the cellular potency of UNC0638 and BIX01294 in J1 mES cells. Consistent with the above results, UNC0638 showed greater cellular potency than BIX01294 (at $48 \mathrm{~h}, \mathrm{IC}_{50}=138$ and 2,041 nM, respectively; Supplementary Fig. 16a). To establish retrovirus silencing, we infected J1 mES cells with an HSC1-EF1a-EGFP-Puromycin retrovirus and selected for transduced cells with a short puromycin treatment. We observed the initial $100 \% \mathrm{EGFP}^{+}$cell population diminish to $30-36 \% \mathrm{EGFP}^{+}$cells as retrovirus silencing was gradually established over 150 $\mathrm{d}$ of extended culture.

To investigate the ability of the probe compounds to reactivate silent retrovirus vectors, we followed EGFP expression by flow cytometry after treatment with UNC0638 (100, 250 or $500 \mathrm{nM})$, BIX01294 $(2 \mu \mathrm{M})$ or UNC0737 (500 nM, as a negative control). Whereas UNC0737 did not reactivate EGFP expression above the $36 \% \mathrm{EGFP}^{+}$cells seen in the untreated sample, UNC0638 reactivated EGFP expression in a concentration-dependent manner to a maximal level of $63 \% \mathrm{EGFP}^{+}$cells at day 10 (Fig. 5a and Supplementary Fig. 16c). BIX01294 reactivated expression reaching the level of 53\% $\mathrm{EGFP}^{+}$cells at day 10, an expression level exceeded when cells were treated with UNC0638 at $250 \mathrm{nM}$, one-eighth the concentration of BIX01294. Moreover, we observed cell morphology changes under BIX01294 treatment, suggesting that this inhibitor may induce cell differentiation. By day 12, BIX01294-treated cells had arrested or died, whereas UNC0638 reactivated EGFP expression in $75 \%$ of cells without showing morphological signs of cell differentiation (Fig. 5a). At day 10 of BIX01294 treatment, only $65 \%$ of cells were positive for the pluripotency marker SSEA1 (Supplementary Fig. 16b). In contrast, UNC0638 treatment maintained expression of the SSEA1 pluripotency marker: the level of marker in cells treated with 100 $\mathrm{nM}$ of UNC0638 (97\% SSEA1 ${ }^{+}$cells) was indistinguishable from that in UNC0737-treated cells or untreated cells. We conclude that inhibition of G9a with UNC0638 functionally 
reactivates silent retrovirus vectors without promoting differentiation into SSEA1- cells and is considerably more potent than BIX01294 treatment.

We next tested whether $M A G E A 2$ and $D U B 1$, genes previously shown to be reactivated in G9a-knockout $\mathrm{mES}$ cells $\mathrm{s}^{25,44}$, could be reactivated with UNC0638 treatment in J1 mES cells. At day 10, DUB1 and MAGEA2 genes were more highly expressed in UNC0638 than in untreated or UNC0737-treated cells (Fig. 5b). Similar to the results for retroviral vector reactivation, mRNA levels of DUB1 and MAGEA2 genes showed a concentrationdependent increase upon treatment with UNC0638. We note that reactivation of endogenous genes occurred by day 3 (Supplementary Fig. 16d), whereas EGFP retrovirus reactivation was first evident by flow cytometry at day 7 (Fig. 5a).

In addition to directly methylating H3K9 (ref. 20), G9a has been reported to indirectly facilitate DNA methylation in $\mathrm{mES}$ cells ${ }^{24-26}$. We first analyzed the presence of H3K9me2 by ChIP on the EGFP provirus and the endogenous MAGEA2 promoter and found that UNC0638 treatment decreased $\mathrm{H} 3 \mathrm{~K} 9 \mathrm{me} 2$ at both targets by day 3, with a further decrease by day 7 (Fig. 5c,d). To test whether this reduction of H3K9me 2 affects DNA methylation, we performed bisulfite sequencing on the retrovirus long terminal repeat and MAGEA2 promoter after $10 \mathrm{~d}$ of treatment. Both regions were hypermethylated in untreated or UNC0737-treated mES cells. In contrast, UNC0638 treatment induced DNA hypomethylation in a concentration-dependent manner (Fig. 5e). These results suggest that inhibition of gene silencing by UNC0638 primarily drives $\mathrm{H} 3 \mathrm{~K} 9 \mathrm{me} 2$ loss to reactivate gene expression and facilitates DNA hypomethylation in $\mathrm{mES}$ cells.

\section{DISCUSSION}

Protein lysine methyltransferase G9a has been implicated in various human diseases including leukemia ${ }^{8}$, prostate cancer ${ }^{8,16}$, liver cancer ${ }^{17}$, lung cancer ${ }^{18}$, drug addiction ${ }^{21}$, mental retardation 22 and maintenance of HIV-1 latency ${ }^{23}$. Given the broad areas of biology in which G9a and GLP have a role, a high-quality chemical probe of these two PKMTs would be very valuable for dissecting the molecular mechanism(s) of these activities, the cell types in which they are relevant and which diseases (if any) would benefit from their inhibition. Here we report the discovery and characterization of UNC0638, which has all the properties of a high-quality chemical probe ${ }^{30}$. (i) UNC0638 is a potent, substratecompetitive inhibitor of $\mathrm{G} 9 \mathrm{a}\left(\mathrm{IC}_{50}<15 \mathrm{nM}, K_{\mathrm{i}}=3 \mathrm{nM}\right)$ and the closely related GLP $\left(\mathrm{IC}_{50}=\right.$ $19 \mathrm{nM}$ ). (ii) It is selective for G9a and GLP over a wide range of epigenetic and nonepigenetic targets. (iii) It is highly active in cells: at $250 \mathrm{nM}$ concentration, it reduces the levels of $\mathrm{H} 3 \mathrm{~K} 9 \mathrm{me} 2$ by $\sim 60-80 \%$ in a variety of cell lines, similar to the reductions seen for shRNA knockdown of G9a and GLP, and modulates expression of known G9a-regulated genes. (iv) UNC0737, an $N$-methyl derivative of UNC0638, is > 300-fold less potent against G9a and GLP, with similar selectivity and cellular toxicity compared to UNC0638, and therefore is a useful negative control. (v) UNC0638 has low cellular toxicity in seven cell lines tested at functional doses. Notably, the greatly improved cellular toxicity/function ratio relative to the previously available probe, BIX01294, makes UNC0638 much more versatile as a chemical probe. (vi) Finally, a useful chemical probe must be available to the biological research community. As such, we have made UNC0638 available through a commercial vendor (Sigma-Aldrich).

Our proteomics and immunofluorescence data show that pharmacologic inhibition of G9a and GLP with UNC0638 leads to global reductions in H3K9me2 levels, comparable to those achieved with shRNAs. However, the genomic regions specifically marked with H3K9me2 vary with cell type and possibly with disease state ${ }^{19-21,23,45}$. Similarly, the cellular levels of G9a and GLP also vary with cell type and disease state ${ }^{8}$. Indeed, we observed considerable 
variation in the global concentration-response behavior of UNC0638 in six cancer cell lines and human fibroblasts. We also observed a marked growth-inhibitory effect in MCF7 cells but not MDA-MB-231 cells at moderate UNC0638 concentrations under which H3K9me2 levels are fully suppressed. Given the association of G9a and GLP with DNMTs ${ }^{46,47}$ and repression of tumor suppressor p53 (refs. 8,48), there may be specific epigenetic cellular states (in particular, H3K9me2-mediated repression of a specific set of genes and/or p53 status) in which cells are selectively vulnerable to G9a and GLP inhibition. UNC0638 will be a useful tool to search for such types of cancer or other disease-related epigenetic states. BIX01294 is likely to be less effective in such studies owing to off-target toxic effects encountered at or near its required concentration for full $\mathrm{H} 3 \mathrm{~K} 9 \mathrm{me} 2$ suppression.

It is notable that most studies of G9a and GLP to date have used knockout or knockdown of G9a and/or GLP, whereas UNC0638 inhibits only the enzymatic function of G9a and GLP, and does not affect the protein and mRNA levels, thereby preserving a potential scaffolding function in the many protein complexes reported for G9a and/or GLP ${ }^{20,46-49}$. For example, it has been shown that catalytic activity of G9a or GLP is not required for all of its function $^{25,26}$. This may explain the milder phenotype of UNC0638 compared to knockdowns of G9a and GLP, and it suggests that UNC0638 can be used to separate enzymatic from non-enzymatic functions of these proteins.

We also show that UNC0638 can reactivate endogenous genes and silenced retroviral reporters in mES cells, further implicating H3K9me2-mediated repression in these processes. Retroviral silencing is a reliable criterion for identification of fully reprogrammed cells and is a good indicator of pluripotency ${ }^{50}$. UNC0638 reduced $\mathrm{H} 3 \mathrm{~K} 9 \mathrm{me} 2$ on endogenous genes and retrovirus vectors within $3 \mathrm{~d}$, and DNA hypomethylation was observed by day 10 , when the cells had already reactivated expression. Together, these results suggest that a cascade of events is involved in the reactivation of silenced genes, and concentrationdependent inhibition of G9a by UNC0638 drives this process. Therefore, UNC0638 is a potent chemical tool for modulating G9a-related activities in cells to alter their expression profiles and epigenetic landscapes, to assist in manipulating their cell identity and phenotype, and to decipher the timing and inter-relationship of H3K9me2 and DNA methylation in gene silencing.

\section{METHODS}

\section{Biochemical assays}

SAHH-coupled assay, peptide displacement, DSF and DSLS assay protocols are described in Supplementary Methods. Morrison $K_{\mathrm{i}}$ and $\mathrm{IC}_{50}$ in G9a MCE assay were determined as described ${ }^{36}$. Details of other selectivity assays are included in Supplementary Methods.

\section{Cell immunostaining (in-cell western)}

We added 2\% (w/v) formaldehyde in PBS to fix cells for $15 \mathrm{~min}$. After five washes with $0.1 \%(\mathrm{v} / \mathrm{v})$ Triton $\times 100$ in PBS, cells were blocked for $1 \mathrm{~h}$ with $1 \%(\mathrm{w} / \mathrm{v})$ BSA in PBS. Three of four replicates were exposed to primary H3K9me2 antibody, Abcam no. 1220 at 1:800 dilution in 1\% BSA and PBS for $2 \mathrm{~h}$. One replicate was reserved as a background control. The wells were washed five times with $0.1 \%$ (v/v) Tween 20 in PBS, then secondary IR800-conjugated antibody (LiCor) and a nucleic acid-intercalating dye, DRAQ5 (LiCor), were added for $1 \mathrm{~h}$. After five washes with $0.1 \%$ Tween 20 in PBS, the plates were read on an Odyssey (LiCor) scanner at $800 \mathrm{~nm}$ (H3K9me2 signal) and $700 \mathrm{~nm}$ (DRAQ5 signal). Fluorescence intensity was quantified, normalized to the background and then to the DRAQ5 signal, and expressed as a percentage of control. 


\section{Quantitative MS analysis of histones}

Histones from MDA-MB-231cells were extracted using standard acid procedures and analyzed after chemical derivatization by propionic anhydride and trypsin as described ${ }^{39}$. Digested histone samples were analyzed by LC-MS/MS on an Orbitrap mass spectrometer as described ${ }^{39}$. All data were manually verified.

\section{ChIP-chip}

ChIP samples were amplified for arrays using a whole-genome amplification (WGA) method (reference is provided in Supplementary Methods). In WGA, DNA fragments are primed to generate a library of DNA fragments with a common end sequence. The library then is replicated using linear, isothermal amplification, followed by a limited round of geometric PCR amplifications. The GenomePlex Complete WGA kit (Sigma) was used for library preparation. ChIP samples concentrated to $10 \mu \mathrm{l}$ were mixed with $2 \mu \mathrm{l}$ librarypreparation buffer and then with $1 \mu l$ library-stabilization solution. Samples were incubated at $95{ }^{\circ} \mathrm{C}$ for $2 \mathrm{~min}$ and afterwards immediately cooled on ice. Each sample was mixed with 1 $\mu 1$ of library-preparation enzyme and incubated as follows: $16^{\circ} \mathrm{C}$ for $20 \mathrm{~min}, 24^{\circ} \mathrm{C}$ for 20 min, $37{ }^{\circ} \mathrm{C}$ for $20 \mathrm{~min}, 75^{\circ} \mathrm{C}$ for $5 \mathrm{~min}, 4^{\circ} \mathrm{C}$ hold. Amplification of the samples was completed with the GenomePlex WGA kit (Sigma). Each sample was combined with $44 \mu \mathrm{l}$ nuclease-free water, $7.5 \mu \mathrm{l}$ Amplification Master Mix, $3 \mu \mathrm{l}$ dNTP/dUTP mix (10 mM dATP, $10 \mathrm{mM} \mathrm{dCTP}, 10 \mathrm{mM}$ dGTP, $8 \mathrm{mM}$ dTTP and $2 \mathrm{mM}$ dUTP) and $5 \mu \mathrm{l} \mathrm{WGA} \mathrm{DNA}$ polymerase. Amplified samples were purified using the QIAquick PCR purification kit (Qiagen) and then processed for array hybridization as described below. Samples exposed to the $\mathrm{H} 3 \mathrm{~K} 9 \mathrm{me} 2$ antibody or IgG control antibody were hybridized to the arrays $(n=2$ per group).

\section{Reactivation of retrovirus expression in mES cells}

$\mathrm{J} 1 \mathrm{mES}$ cells were cultured (reference is provided in Supplementary Methods) in DMEM

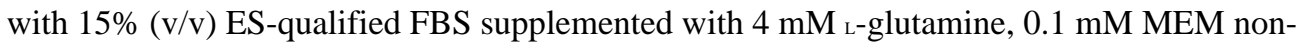
essential amino acids, $1 \mathrm{mM}$ sodium pyruvate, $0.55 \mathrm{mM}$ 2-mercaptoethanol and purified recombinant leukemia inhibitory factor on $0.1 \%$ gelatin-coated plates. Cells were infected with a self-inactivated $\mathrm{HSC} 1$ retroviral vector (reference is provided in Supplementary Methods) engineered to harbor an EGFP-Puromycin biscistronic reporter gene controlled by the human EF1a promoter. EGFP gene expression was analyzed by flow cytometry. Pluripotency of mES cells was tested by SSEA1 (a surface maker of mouse undifferentiated cells) immunostaining and also measured by flow cytometry. Briefly, to perform flow cytometry, we fixed trypsinized cells with $2 \%$ formaldehyde in phosphate-buffered saline with $2 \%(\mathrm{v} / \mathrm{v})$ FBS for $10 \mathrm{~min}$ at room temperature. Cells were then suspended in PBS with $2 \%(\mathrm{v} / \mathrm{v})$ of serum (flow buffer) and filtered through $70-\mu$ m nylon membranes. EGFP expression analyses were performed by LSRII flow cytometer (Becton-Dickinson) using CellQuest Pro software. SSEA1 (a surface maker of mouse undifferentiated cells) immunostaining was performed on non-permeabilized fixed cells. They were incubated with mouse IgM antibody to SSEA1 (DSHB, MC-480) for $30 \mathrm{~min}$ at $4{ }^{\circ} \mathrm{C}$. After being washed three times with flow buffer, cells were incubated for $30 \mathrm{~min}$ with secondary antibody, Phycoerythrin-Cy5.5 (PE-Cy5.5) anti-mouse IgM (eBioscience), at $4{ }^{\circ} \mathrm{C}$. Cells were washed three times in the flow buffer, and SSEA1 immunostaining was analyzed by LSRII flow cytometer. We excluded cell debris were excluded from analysis by using forward- and sidescatter gating. Uninfected J1 ES cell line was used as a negative control to adjust EGFP fluorescence measurements. SSEA1 immunostaining of mouse embryonic fibroblast was used as a negative control cell line for SSEA1 cell measurement. Reactivation of endogenous genes, ChIP of endogenous gene and retrovirus, and DNA methylation analysis in $\mathrm{mES}$ cells are described in Supplementary Methods. 


\section{Additional methods}

Synthesis of UNC0638 and UNC0737, UNC0638 mechanism-of-action and kinetic studies, determination of X-ray crystal structure of the G9a-UNC0638-SAH complex, UNC0638 stability studies, mouse drug metabolism and pharmacokinetic studies, cell growth, MTT, shRNA, ChIP, western blotting, immunofluorescence microscopy, clonogenicity, immunostaining flow cytometry, reverse transcription-qPCR, DNA extraction, enrichment of unmethylated DNA fraction, and microarray experiments and data analysis are described in Supplementary Methods.

\section{Accession codes}

Protein Data Bank: Coordinates and structure factors for the cocrystal structure of the G9aUNC0638-SAH complex have been deposited with accession code 3RJW.

\section{Supplementary Material}

Refer to Web version on PubMed Central for supplementary material.

\section{Acknowledgments}

We thank A. Tumber for JMJD2E assay support; J. Moffat (University of Toronto) for the gift of shRNAs; R. Bristow (University Health Network) for RV221 and PC3 cells; T. Hajian and F. Syeda for protein purification; G. Senisterra for contributing to DSF and DSLS data analysis; M. Herold for graphical design and illustration; I. Korboukh, M. Herold and J. Yost for critical reading of the manuscript; and R. Trump and C. Yates for helpful discussion. The research described here was supported by the National Institute of General Medical Sciences, US National Institutes of Health (NIH; grant RC1GM090732), the Carolina Partnership and University Cancer Research Fund from the University of North Carolina at Chapel Hill, the US National Science Foundation (NSF), the Ontario Research Fund, the Ontario Ministry of Health and Long-term Care and the Structural Genomics Consortium. The Structural Genomics Consortium is a registered charity (number 1097737) that receives funds from the Canadian Institutes for Health Research (CIHR), the Canada Foundation for Innovation, Genome Canada through the Ontario Genomics Institute, GlaxoSmithKline, Karolinska Institutet, the Knut and Alice Wallenberg Foundation, the Ontario Innovation Trust, the Ontario Ministry for Research and Innovation, Merck \& Co. Inc., the Novartis Research Foundation, the Swedish Agency for Innovation Systems, the Swedish Foundation for Strategic Research and the Wellcome Trust. C.H.A. holds a Canada Research Chair in Structural Genomics. V.L. is supported by a CIHR fellowship. A.P. is supported by grants from the CIHR (199170 and 186007) and from the NIH (MH074127, MH088413, DP3DK085698 and HG004535). A.P. is Tapscott Chair in Schizophrenia Studies and a Senior Fellow of the Ontario Mental Health Foundation. J.E. is supported by CIHR grant IG1-102956. B.A.G. is supported by grants from the NSF (Early Faculty CAREER award and CBET-0941143), the American Society for Mass Spectrometry and the NIH Office of the Director (DP2OD007447). P.A.D. is supported by NIH postdoctoral fellowship F32 NRSA.

\section{References}

1. Kouzarides T. Chromatin modifications and their function. Cell. 2007; 128:693-705. [PubMed: 17320507]

2. Martin C, Zhang Y. The diverse functions of histone lysine methylation. Nat. Rev. Mol. Cell Biol. 2005; 6:838-849. [PubMed: 16261189]

3. Jenuwein T, Allis CD. Translating the histone code. Science. 2001; 293:1074-1080. [PubMed: 11498575]

4. Bernstein BE, Meissner A, Lander ES. The mammalian epigenome. Cell. 2007; 128:669-681. [PubMed: 17320505]

5. Gelato KA, Fischle W. Role of histone modifications in defining chromatin structure and function. Biol. Chem. 2008; 389:353-363. [PubMed: 18225984]

6. Strahl BD, Allis CD. The language of covalent histone modifications. Nature. 2000; 403:41-45. [PubMed: 10638745]

7. Huang J, et al. Repression of p53 activity by Smyd2-mediated methylation. Nature. 2006; 444:629632. [PubMed: 17108971] 
8. Huang J, et al. G9A and GLP methylate lysine 373 in the tumor suppressor p53. J. Biol. Chem. 2010; 285:9636-9641. [PubMed: 20118233]

9. Rathert P, et al. Protein lysine methyltransferase G9a acts on non-histone targets. Nat. Chem. Biol. 2008; 4:344-346. [PubMed: 18438403]

10. Huang J, et al. p53 is regulated by the lysine demethylase LSD1. Nature. 2007; 449:105-108. [PubMed: 17805299]

11. Copeland RA, Solomon ME, Richon VM. Protein methyltransferases as a target class for drug discovery. Nat. Rev. Drug Discov. 2009; 8:724-732. [PubMed: 19721445]

12. Rea $\mathrm{S}$, et al. Regulation of chromatin structure by site-specific histone $\mathrm{H} 3$ methyltransferases. Nature. 2000; 406:593-599. [PubMed: 10949293]

13. Cole PA. Chemical probes for histone-modifying enzymes. Nat. Chem. Biol. 2008; 4:590-597. [PubMed: 18800048]

14. Esteller M. Epigenetics in cancer. N. Engl. J. Med. 2008; 358:1148-1159. [PubMed: 18337604]

15. Tachibana M, et al. G9a histone methyltransferase plays a dominant role in euchromatic histone H3 lysine 9 methylation and is essential for early embryogenesis. Genes Dev. 2002; 16:17791791. [PubMed: 12130538]

16. Kondo Y, et al. Downregulation of histone H3 lysine 9 methyltransferase G9a induces centrosome disruption and chromosome instability in cancer cells. PLoS ONE. 2008; 3:e2037. [PubMed: 18446223]

17. Kondo Y, et al. Alterations of DNA methylation and histone modifications contribute to gene silencing in hepatocellular carcinomas. Hepatol. Res. 2007; 37:974-983. [PubMed: 17584191]

18. Watanabe $\mathrm{H}$, et al. Deregulation of histone lysine methyltransferases contributes to oncogenic transformation of human bronchoepithelial cells. Cancer Cell Int. 2008; 8:15. [PubMed: 18980680]

19. Goyama S, et al. EVI-1 interacts with histone methyltransferases SUV39H1 and G9a for transcriptional repression and bone marrow immortalization. Leukemia. 2010; 24:81-88. [PubMed: 19776757]

20. Tachibana M, et al. Histone methyltransferases G9a and GLP form heteromeric complexes and are both crucial for methylation of euchromatin at H3-K9. Genes Dev. 2005; 19:815-826. [PubMed: 15774718]

21. Maze I, et al. Essential role of the histone methyltransferase G9a in cocaine-induced plasticity. Science. 2010; 327:213-216. [PubMed: 20056891]

22. Schaefer A, et al. Control of cognition and adaptive behavior by the GLP/G9a epigenetic suppressor complex. Neuron. 2009; 64:678-691. [PubMed: 20005824]

23. Imai K, Togami H, Okamoto T. Involvement of histone H3 Lysine 9 (H3K9) methyl transferase G9a in the maintenance of HIV-1 latency and its reactivation by BIX01294. J. Biol. Chem. 2010; 285:16538-16545. [PubMed: 20335163]

24. Link PA, et al. Distinct roles for histone methyltransferases G9a and GLP in cancer germ-line antigen gene regulation in human cancer cells and murine embryonic stem cells. Mol. Cancer Res. 2009; 7:851-862. [PubMed: 19531572]

25. Tachibana M, Matsumura Y, Fukuda M, Kimura H, Shinkai Y. G9a/GLP complexes independently mediate H3K9 and DNA methylation to silence transcription. EMBO J. 2008; 27:2681-2690. [PubMed: 18818694]

26. Dong KB, et al. DNA methylation in ES cells requires the lysine methyltransferase G9a but not its catalytic activity. EMBO J. 2008; 27:2691-2701. [PubMed: 18818693]

27. Shi Y, et al. Induction of pluripotent stem cells from mouse embryonic fibroblasts by Oct 4 and Klf4 with small-molecule compounds. Cell Stem Cell. 2008; 3:568-574. [PubMed: 18983970]

28. Shi Y, et al. A combined chemical and genetic approach for the generation of induced pluripotent stem cells. Cell Stem Cell. 2008; 2:525-528. [PubMed: 18522845]

29. Kubicek S, et al. Reversal of H3K9me2 by a small-molecule inhibitor for the G9a histone methyltransferase. Mol. Cell. 2007; 25:473-481. [PubMed: 17289593]

30. Frye SV. The art of the chemical probe. Nat. Chem. Biol. 2010; 6:159-161. [PubMed: 20154659] 
31. Liu F, et al. Discovery of a 2,4-diamino-7-aminoalkoxyquinazoline as a potent and selective inhibitor of histone lysine methyltransferase G9a. J. Med. Chem. 2009; 52:7950-7953. [PubMed: 19891491]

32. Liu F, et al. Protein lysine methyltransferase G9a inhibitors: design, synthesis, and structure activity relationships of 2,4-diamino-7-aminoalkoxyquinazolines. J. Med. Chem. 2010; 53:58445857. [PubMed: 20614940]

33. Chang Y, et al. Adding a lysine mimic in the design of potent inhibitors of histone lysine methyltransferases. J. Mol. Biol. 2010; 400:1-7. [PubMed: 20434463]

34. Chang Y, et al. Structural basis for G9a-like protein lysine methyltransferase inhibition by BIX-01294. Nat. Struct. Mol. Biol. 2009; 16:312-317. [PubMed: 19219047]

35. Collazo E, Couture JF, Bulfer S, Trievel RC. A coupled fluorescent assay for histone methyltransferases. Anal. Biochem. 2005; 342:86-92. [PubMed: 15958184]

36. Wigle TJ, et al. Accessing protein methyltransferase and demethylase enzymology using microfluidic capillary electrophoresis. Chem. Biol. 2010; 17:695-704. [PubMed: 20659682]

37. Morrison JF. Kinetics of the reversible inhibition of enzyme-catalysed reactions by tight-binding inhibitors. Biochim. Biophys. Acta. 1969; 185:269-286. [PubMed: 4980133]

38. Zee BM, et al. In vivo residue-specific histone methylation dynamics. J. Biol. Chem. 2010; 285:3341-3350. [PubMed: 19940157]

39. Plazas-Mayorca MD, et al. Quantitative proteomics reveals direct and indirect alterations in the histone code following methyltransferase knockdown. Mol. Biosyst. 2010; 6:1719-1729. [PubMed: 20577673]

40. Barski A, et al. High-resolution profiling of histone methylations in the human genome. Cell. 2007; 129:823-837. [PubMed: 17512414]

41. Rice JC, et al. Histone methyltransferases direct different degrees of methylation to define distinct chromatin domains. Mol. Cell. 2003; 12:1591-1598. [PubMed: 14690610]

42. Vakoc CR, Mandat SA, Olenchock BA, Blobel GA. Histone H3 lysine 9 methylation and HP1gamma are associated with transcription elongation through mammalian chromatin. Mol. Cell. 2005; 19:381-391. [PubMed: 16061184]

43. Wolf D, Goff SP. TRIM28 mediates primer binding site-targeted silencing of murine leukemia virus in embryonic cells. Cell. 2007; 131:46-57. [PubMed: 17923087]

44. Yokochi T, et al. G9a selectively represses a class of late-replicating genes at the nuclear periphery. Proc. Natl. Acad. Sci. USA. 2009; 106:19363-19368. [PubMed: 19889976]

45. Hosey AM, Chaturvedi CP, Brand M. Crosstalk between histone modifications maintains the developmental pattern of gene expression on a tissue-specific locus. Epigenetics. 2010; 5:273-281. [PubMed: 20424518]

46. Epsztejn-Litman S, et al. De novo DNA methylation promoted by G9a prevents reprogramming of embryonically silenced genes. Nat. Struct. Mol. Biol. 2008; 15:1176-1183. [PubMed: 18953337]

47. Estève PO, et al. Direct interaction between DNMT1 and G9a coordinates DNA and histone methylation during replication. Genes Dev. 2006; 20:3089-3103. [PubMed: 17085482]

48. Chen L, et al. MDM2 recruitment of lysine methyltransferases regulates p53 transcriptional output. EMBO J. 2010; 29:2538-2552. [PubMed: 20588255]

49. Fritsch L, et al. A subset of the histone H3 lysine 9 methyltransferases Suv39h1, G9a, GLP, and SETDB1 participate in a multimeric complex. Mol. Cell. 2010; 37:46-56. [PubMed: 20129054]

50. Stadtfeld M, Maherali N, Breault DT, Hochedlinger K. Defining molecular cornerstones during fibroblast to iPS cell reprogramming in mouse. Cell Stem Cell. 2008; 2:230-240. [PubMed: 18371448] 

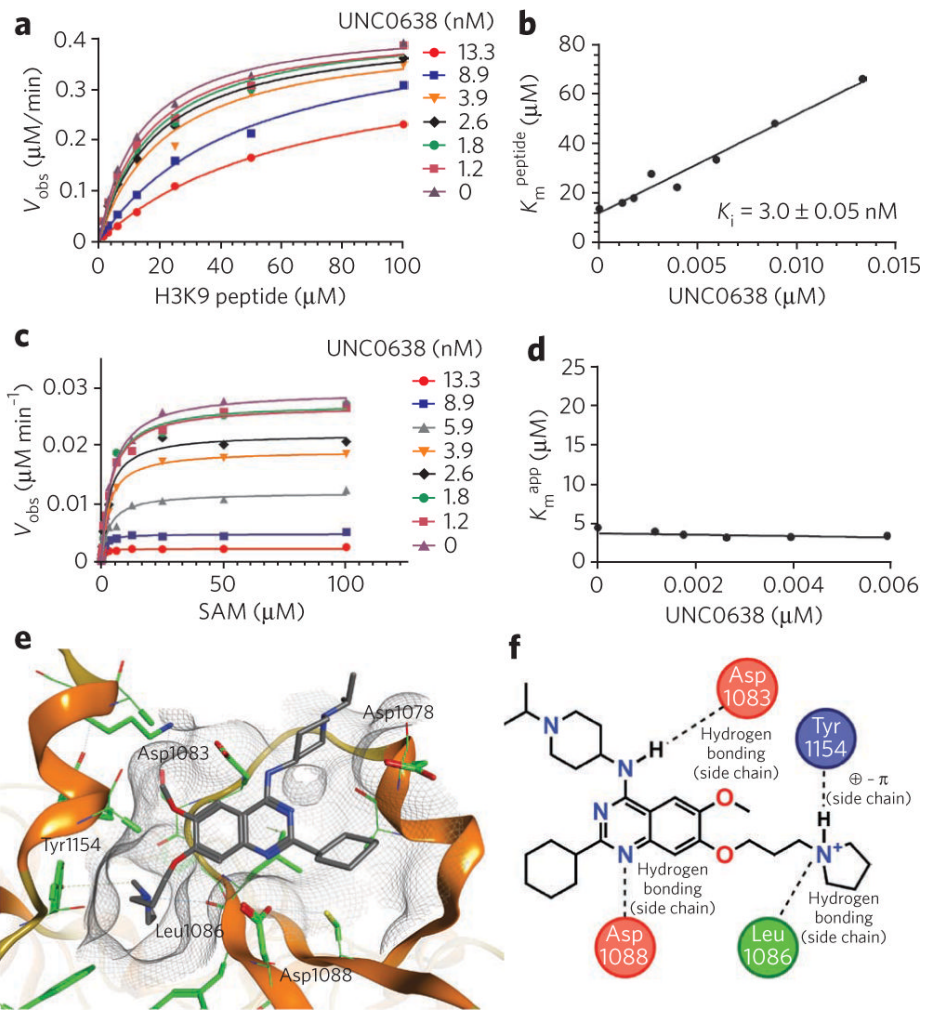

Figure 1. UNC0638 competes with the peptide substrate but not with the cofactor SAM We determined the velocity of the reaction by measuring the conversion of substrate to product at six time points spanning $100 \mathrm{~min}$, analyzed these data by linear regression to determine initial steady-state enzyme velocity and fitted them to Michaelis-Menten kinetics. The $K_{\mathrm{m}}$ values of the peptide and SAM were then plotted as a function of UNC0638 concentrations. (a,b) UNC0638 is competitive with the H3K9 peptide substrate, as $K_{\mathrm{m}}{ }^{\text {peptide }}$ increases linearly with compound concentration. (c,d) UNC0638 does not compete with the cofactor SAM, as $K_{\mathrm{m}}{ }^{\text {app }}$ was not affected by the compound. (e,f) The X-ray cocrystal structure of the G9a-UNC0638-saH complex confirms the mechanism of action of UNC0638. UNC0638 (in gray, blue and red sticks) occupies the peptide binding groove and does not interact with the SAM binding pocket. The 7-(3-pyrrolidin-1-yl-) propoxy side chain of UNC0638 interacts with the lysine binding channel. 


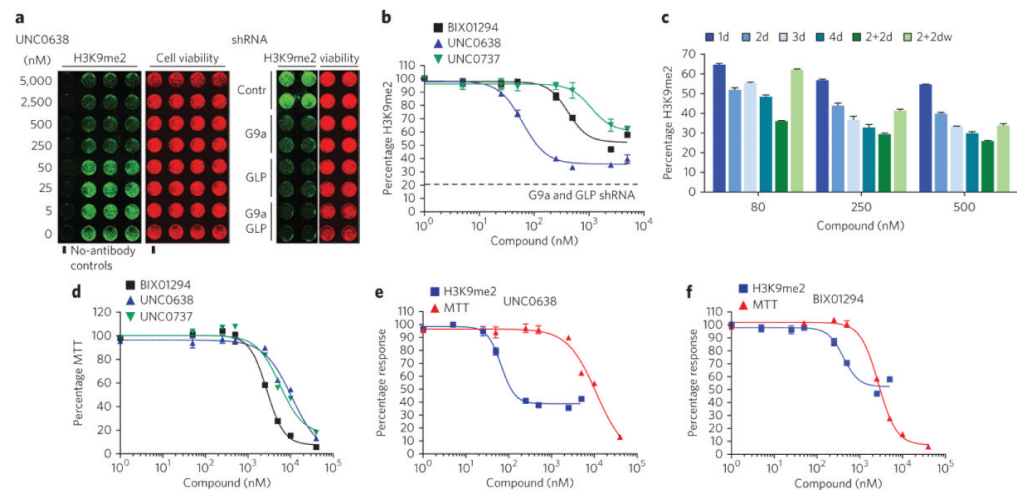

Figure 2. UNC0638 inhibits cellular H3K9 dimethylation and shows good separation of functional potency and toxicity in MDA-MB-231 cells

(a) UNC0638 (48 h) or G9a and/or GLP shRNAs, reduced H3K9 dimethylation levels. H3K9me2 antibody was used for cell immunostaining (in-cell western) and results normalized to cell number measured by uptake nucleic acid dye (DRAQ5). (b) UNC0638 was considerably more potent than BIX01294 and UNC0737 (negative control) in reducing cellular H3K9me2 levels, which were measured after MDA-MB-231 cells were treated with inhibitors for $48 \mathrm{~h}$. Dashed line indicates level of H3K9me2 resulting from G9a and GLP knockdown. (c) Cellular levels of $\mathrm{H} 3 \mathrm{~K} 9 \mathrm{me} 2$ were progressively reduced from $1 \mathrm{~d}$ to $4 \mathrm{~d}$ exposure to UNC0638 at three concentrations $\left(80 \mathrm{nM}\right.$, representing $\mathrm{IC}_{50} ; 250 \mathrm{nM}$, representing $\mathrm{IC}_{90}$; and $500 \mathrm{nM}$, representing $\left.2 \times \mathrm{IC}_{90}\right)$. The reductions with $250-\mathrm{nM}$ and 500-nM treatments after $4 \mathrm{~d}$ were equal or very close to that of G9a and GLP knockdown cells. Refreshing the inhibitor after $2 \mathrm{~d}(2+2 \mathrm{~d})$ increased inhibition by UNC0638 at $80 \mathrm{nM}$ but had little further effect at 250 and $500 \mathrm{nM}$. The effects of UNC0638 were long-lasting. In cells with $2 \mathrm{~d}$ exposure to UNC0638, levels of $\mathrm{H} 3 \mathrm{~K} 9 \mathrm{me} 2$ remained low after washout of compound followed by $2 \mathrm{~d}$ incubation without the inhibitor $(2+2 \mathrm{dw})$. (d) UNC0638 and UNC0737 had lower cellular toxicity than BIX01294 in MTT (3-(4,5-dimethylthiazol-2yl)-2,5-diphenyl tetrazolium bromide)) assays. (e,f) UNC0638 had good separation of functional potency (decrease in $\mathrm{H} 3 \mathrm{~K} 9 \mathrm{me} 2$ levels) and toxicity (from the MTT assay), whereas BIX01294 had poor separation of these effects. 

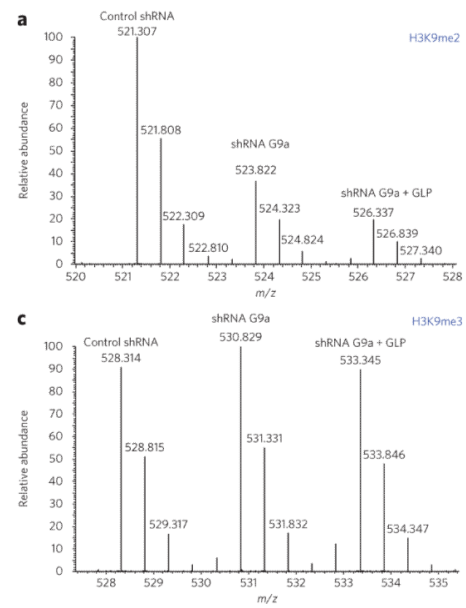
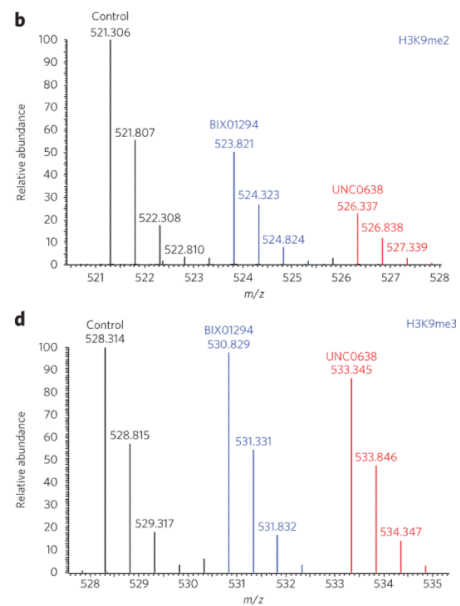

Figure 3. Quantitative MS analysis of histone post-translational modifications in MDA-MB-231 cells

(a-d) MS of doubly charged peptides (KSTGGKAPR) corresponding to H3K9me2 (a,b) and H3K9me3 (c,d). In a,c, cells were treated with indicated shRNAs (control, D0 propionyl labeled; G9a, D0,D5 propionyl labeled, $\sim 2.5 \mathrm{~m} / z$ heavier than the control; G9a + GLP, D5,D5 propionyl labeled, $\sim 5 \mathrm{~m} / z$ heavier than the control). In $\mathbf{b}, \mathbf{d}$, cells were mock-treated (control, D0 propionyl labeled) or treated with $1 \mu \mathrm{M}$ of BIX01294 (D0,D5 propionyl labeled, $\sim 2.5 \mathrm{~m} / z$ heavier than the control) or UNC0638 (D5,D5 propionyl labeled, $\sim 5 \mathrm{~m} / z$ heavier than the control) for $48 \mathrm{~h}$. 
a
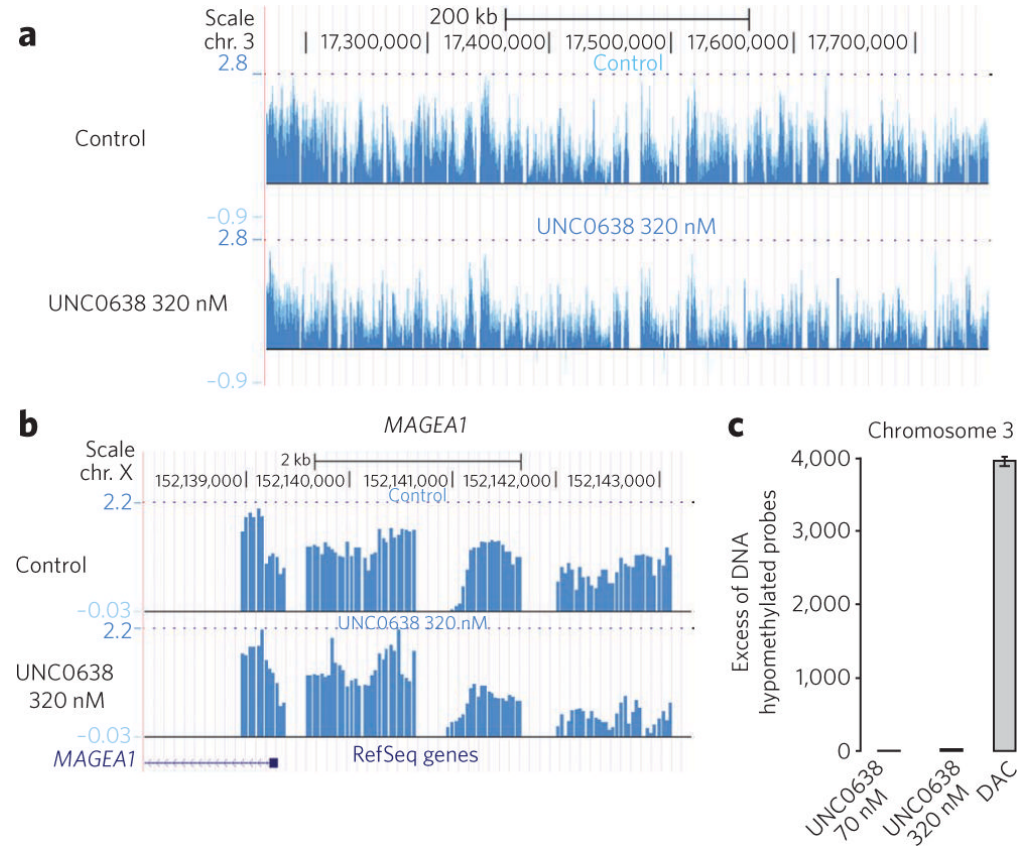

Figure 4. Effects of UNC0638 on H3K9me2 and DNA methylation

(a) Example of a genomic region (3p24.3) showing reductions in $\mathrm{H} 3 \mathrm{~K} 9 \mathrm{me} 2$ after UNC0638 exposure $(P=2.0 \times 10-10)$. Light blue bars show the log ratios of anti-H3K9me2 to IgG in control (top) and treated (bottom) samples. (b) Administration of UNC0638 decreased $\mathrm{H} 3 \mathrm{~K} 9 \mathrm{me} 2$ in the MAGEA1 promoter. Log ratios are shown as in $\mathbf{a}$. The promoter was defined to be 4 kilobase pairs upstream and 0.5 kilobase pairs downstream of the transcription start site. (c) UNC0638 did not change DNA methylation levels. MCF7 cells were exposed to either UNC0638 (at 70 or $320 \mathrm{nM}$ ), 5-azacytidine (DAC) or control. $y$-axis scale is the excess of the number of significantly hypomethylated probes over the number of hypermethylated probes on chromosome 3. Significance cutoff was set at $P=10-3$ for twosample $t$-test between treated and control log intensities. 

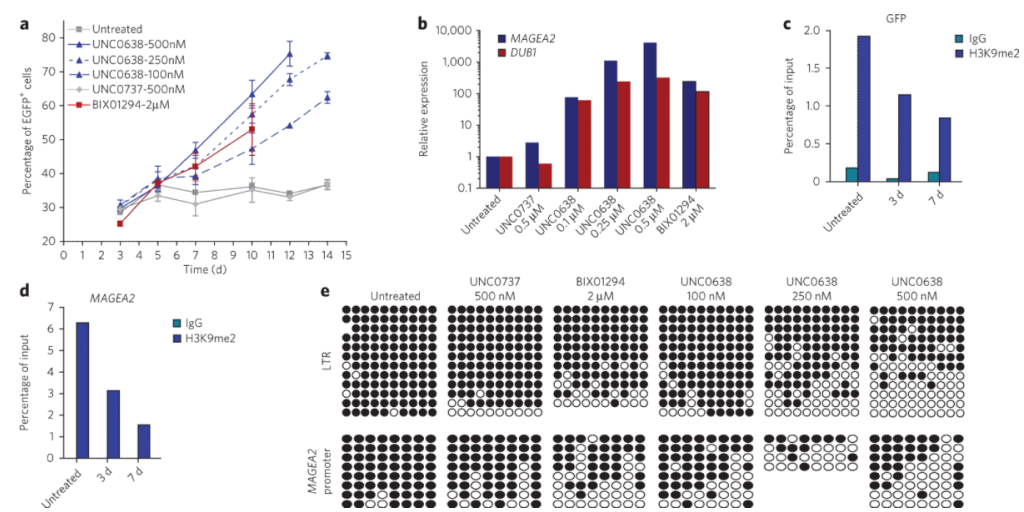

Figure 5. UNC0638 reactivates a silent EGFP retrovirus vector and G9a-regulated endogenous genes in mES cells

(a) Time course of EGFP retrovirus activation during indicated treatments in J1 mES cells infected by HSC1-EF1a-EGFP-Puromycin retroviral vector. Plotted percentage of EGFP expression is the mean of the percentage of $\mathrm{EGFP}^{+}$cells in three independent experiments. Error bars, s.d. (b) Analysis of mRNA levels of two G9a-regulated endogenous genes (MAGEA2 and DUB1) in $\mathrm{J} 1 \mathrm{mES}$ cells treated for $10 \mathrm{~d}$ with indicated compounds. The graph shows the normalized expression of $M A G E A 2$ and $D U B 1$ relative to the mRNA level detected in untreated cells $(\Delta(\Delta \mathrm{Ct}))$. (c,d) ChIP analysis of $\mathrm{H} 3 \mathrm{~K} 9 \mathrm{me} 2$ enrichment at the EGFP gene (c) and MAGEA2 promoter (d) in cells treated with UNC0638 (500 nM) for 3 or $7 \mathrm{~d}$. (e) Analysis of DNA methylation in the long terminal repeat (LTR) of the HSC1EF1a-EGFP-Puromycin retroviral vector and in the $M A G E A 2$ promoter after $10 \mathrm{~d}$ of treatment. 


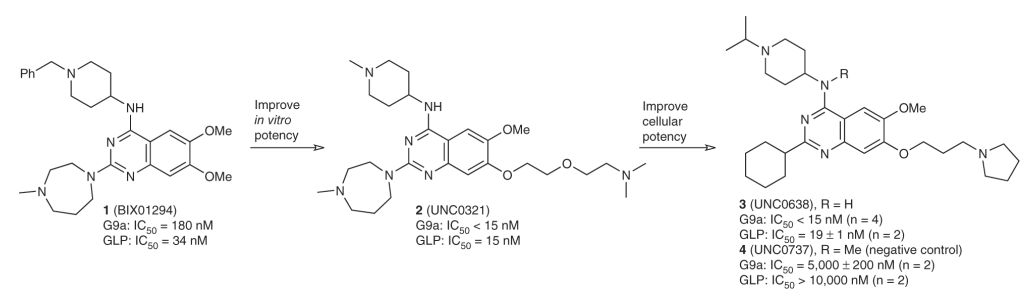

Scheme 1. Discovery of UNC0638

Structure-based design and SAR exploration of the quinazoline template represented by BIX01294 led to the identification of UNC0321, a G9a and GLP inhibitor with high in vitro potency but poor cellular potency. The design and synthesis of several generations of new analogs aimed at improving cell membrane permeability while maintaining high in vitro potency resulted in the discovery of UNC0638, which has balanced in vitro potency and physicochemical properties aiding cell penetration. UNC0737, the $N$-methyl analog of UNC0638, was discovered as a structurally similar but less potent G9a and GLP inhibitor for use as a negative control. 
Table 1

Selectivity of UNC0638 against epigenetic targets

\begin{tabular}{lccc} 
Target & $\mathbf{I C}_{\mathbf{5 0}}(\mathbf{n m})^{\boldsymbol{a}}$ & $\boldsymbol{K}_{\mathbf{i}}(\mathbf{n m})^{\boldsymbol{a}}$ & $\mathbf{T m}$ shift $\left.{ }^{\circ} \mathbf{C}\right)^{\boldsymbol{b}}$ \\
\hline G9a & $<^{c}$ & $3 \pm 0.05^{d}$ & 4 \\
GLP & $19 \pm 1^{c}$ & 8 \\
SUV39H2 & $>10,000^{c}$ & $\mathrm{NT}$ \\
SUV39H1 & $>10,000^{e}$ & $\mathrm{NT}$ \\
SETD7 & $>10,000^{c}$ & $\mathrm{NT}$ \\
SMYD3 & $\mathrm{NT}$ & $\mathrm{ND}$ \\
MLL & $>10,000^{e}$ & $\mathrm{NT}$ \\
EZH2 & $>10,000^{e}$ & $\mathrm{NT}$ \\
DOT1L & $\mathrm{NT}$ & $\mathrm{ND}$ \\
SETD8 & $>10,000^{c}$ & $\mathrm{ND}$ \\
PRDM1 & $\mathrm{NT}$ & $\mathrm{ND}$ \\
PRDM10 & $\mathrm{NT}$ & $\mathrm{ND}$ \\
PRDM12 & $\mathrm{NT}$ & $\mathrm{ND}$ \\
PRMT1 & $>10,000^{e}$ & $\mathrm{NT}$ \\
PRMT3 & $>10,000^{c}$ & $\mathrm{ND}$ \\
HTATIP & $\mathrm{NT}$ & $\mathrm{ND}$ \\
JMJD2E & $4,500 \pm 1,100^{f}$ & $\mathrm{NT}$ \\
DNMT1 & $107,000 \pm 6,000^{g}$ & \\
\hline & &
\end{tabular}

${ }^{a}$ IC50 or $K_{\mathrm{i}}$ values are the average of at least two separate experiments.

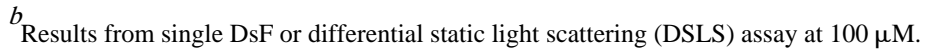

$c_{\text {SAHH-coupled assay results. }}$

dMCE assay results.

$e_{\text {Assay results from BPs Bioscience. }}$

$f_{\text {Alphascreen assay results. }}$

$g_{\text {Radioactive methyl transfer assay results. NT, not tested. ND, not detected. }}$ 